executed. By the exclusion of much that is doubtful and by a concise method of expression the author has managed to compress into this book much that is usefnl and important regarding what is known of nasal diseases. A judicious selection of prescriptions is here and there inserted. The size of this work forbids its pretence to be anything like a complete treatise on the subject. At the same time we think the directions for operating in some instances are too meagre and we note with surprise how little attention is drawn to the methods of operation for adenoid growths and their symptoms and pathology. This little book will, however, be a useful addition to any medical man's library.

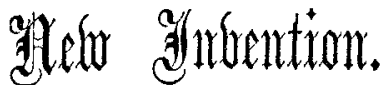

\section{A SIMPLE AND PORTABLE SPIROMETER.}

THE spirometer is an instrument now little used, more on account, perhaps, of its bulk and cost than anything else. This infrequency of use may also be attributable to the fact that the instrument has one use only-viz., the capability of determining one condition-vital capacity, without affording indications of the correlating factors which modify it, and the most important of these is expiratory

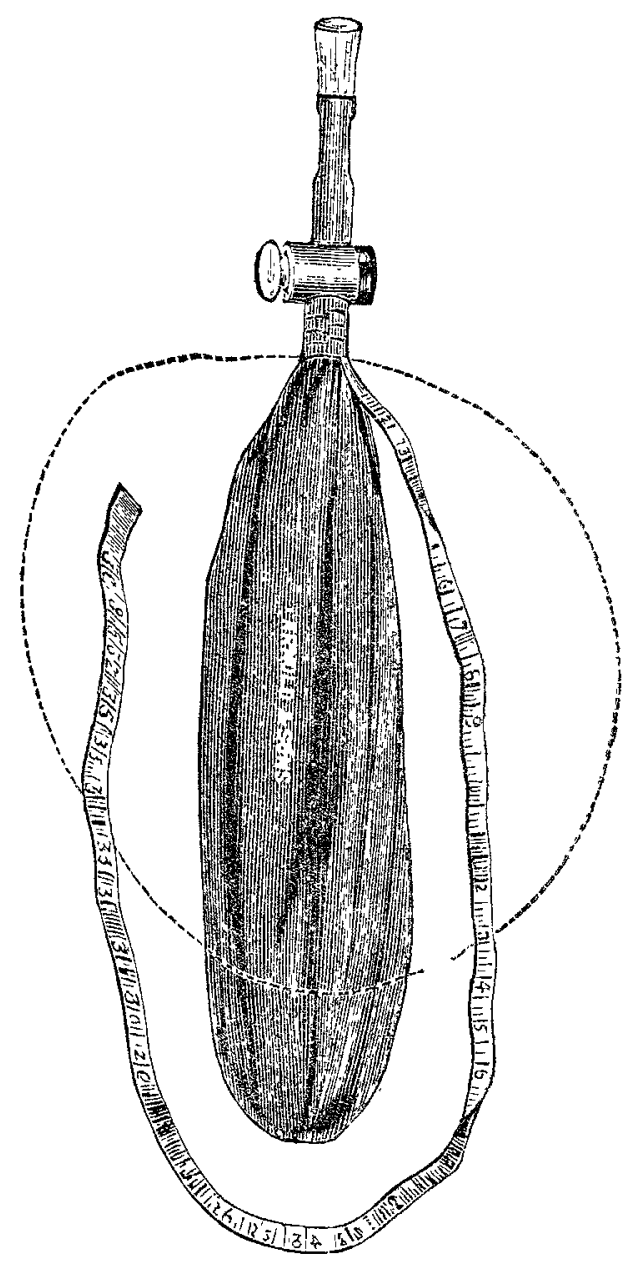

force. The accompanying engraving represents a very simple. practically efficient spirometer made for me by Messrs. Anold. Its capacity will prove equal to all requirements, It consists of an elastic bag exceedingly easy to distend, with a tape affixed whereby the degree of distension can be measured. Expiratory force can be determined by employing thicker bags, which require greater effort to distend, or by making use of a broad elastic tape to surround the bag, instead of the tape generally used.

Crouch-end:

\section{THE MEETING OF FELLOWS AT THE ROYAL COLLEGE OF SURGEONS OF ENGLAND.}

IT was scarcely to be expected that a meeting of Fcllows of the Royal College of Surgeons of England summoned by the Council without any definite object in view and without any programme of business stated in the summons would lead to any definite results. If it had been originally intended to place before the Fellows all the resolutions which the Council passed at the instance of the committee which sat to consider what further advantages could be extended to the Fellows and the best mode of celebrating the Jubilee of the Fellowship; it is to be regretted that this was not done. Instead of this, the President informed the meeting that there was nothing particular to be brought forward for discussion and then invited the Fellows present to express an opinion only upon the proposals which had been made in regard to the celebration of the Jubilee, carefully excluding the more important resolutions with regard to advantages to the Fellows. Strange as it may appear, there were several Fellows present who were not aware that any resolutions whatever had been passed by the Conncil which concerned their interests. Consequently a natural complaint was elicited from Mr. Crosby that no notice had been sent to him from the Secretary intimating that it was the intention of the Council to celebrate the Jubilee of the Fellowship. Thereupon the President directed the Secretary to procure and to read to the meeting the report on the public celebration, which was done; but the meeting not having any organisation or cohesion, and having assembled in a spirit of curiosity and readiness to receive whatever might be vouchsafed to them, did not show any signs of a desire for more substantial fare. A long pause ensued, and but for the intervention of Mr. Holmes the assembly might have dispersed without any discussion. Mr. Holmes rose to express his gratification at the action of the Council in calling the Fellows together, his approval of the arrangements for celebrating the Jubilee of the Fellowship, and to call attention to the desirability of the Council consulting the Fellows of the College before coming to a decision on matters of great professional interest and importance, instancing the University question and the five years' curriculum. His remarks were conched in a friendly and courteous vein and there was nothing to invite the attack which was made on him by Mr. Christopher Heath. Most gladly should we have abstained from alluding to the subject if a sense of professional duty did not compel us to deprecate the spirit and substance of Mr. Heath's remarks, and we shail only add that the sense of the meeting was admirably expressed by Dr. W. J. Collins, who in a few well-chosen words expressed his deep regret at such an episode occurring at a friendly conference at which it was understood that the hatchet was to be buried. Dr. Collins concluded with a suggestion, of which Mr. Howse expressed his approvalviz., that the Fellows should choose a body like the annual Committee of Convocation of the University of London to consider questions affecting the interests of the Fellows and to be the medium of communication between the Fellows and the Council Before another meeting of Fellows is called we must hope that the Council of the College will see its way to adopt regulations under which the proceedings may be conducted in a formal and businesslike manner. We trust also that the President or other chairman at these meetings will not allow personal attacks to be made in the future.

Victoria Infirmary Dispensary, Glasgow.The ceremony of inaugurating the dispensary in St. James. street, Paisley-road in connexion with this infirmary, took place on the 4th inst. It had been for some time the intention of the governors to establish district dispensaries on the south side, but hitherto they had no funds to spare for that purpose. Under these circumstances Mr. A. Cameron Corbett, on behalf of himself and his sister, had presented the governors with 1000 guineas, which would enable them to equip the dispensary and work it for the next three years. It will be opened to the public on Wednesday next. 